\title{
COVID-19 in intensive care. Some necessary steps for health care workers
}

\author{
Nipun Malhotra ${ }^{1}$, Nitesh Gupta ${ }^{1}$, Somya Ish ${ }^{2}$, Pranav Ish ${ }^{1}$ \\ ${ }^{1}$ Department of Pulmonary, Critical Care and Sleep Medicine, Vardhman Mahavir Medical College and Safdarjung \\ Hospital, New Delhi; ${ }^{2}$ Department of Ophthalmology, Dr. Ram Manohar Lohia Hospital, New Delhi, India
}

\begin{abstract}
To the Editor
Due to the nature of their profession, health care personnel (HCP) have always been easy targets for transmission of communicable diseases like COVID-19. Shielding HCPs is of consequential significance in ensuring continued health care for the whole population in addition to reducing further spread. Close contact, repeated contact and prolonged contact are unavoidable in the intensive care (IC) environment. It is not uncommon for IC-HCPs to get carried away during an emergent situation, such as that posed by a suddenly deteriorating patient, and forgo the protective barriers that protect them from contracting a communicable infection. Some notable precautionary measures are mentioned below. This is by no means an exhaustive list.
\end{abstract}

\section{Minimize surface contact - think before you touch}

Central to the prevention of transmission of infective pathogens is to reduce contact. All unnecessary contact with

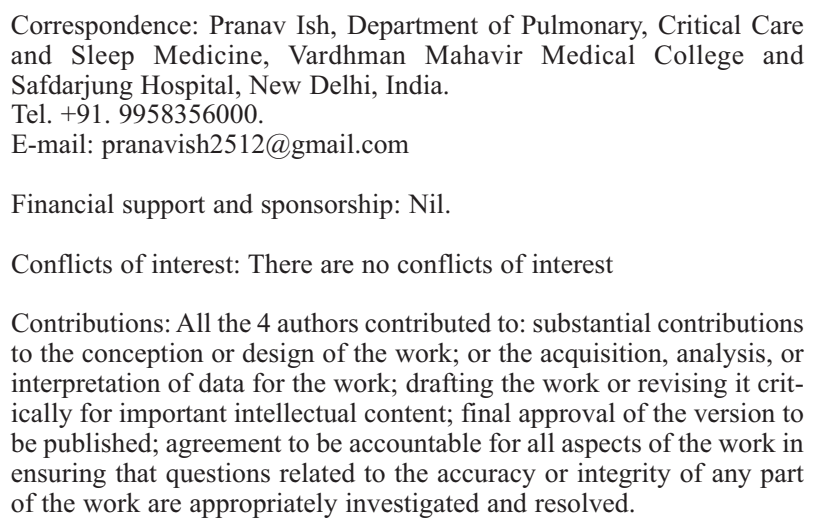

E-mail: pranavish2512@gmail.com

Financial support and sponsorship: Nil.

Conflicts of interest: There are no conflicts of interest

Contributions: All the 4 authors contributed to: substantial contributions to the conception or design of the work; or the acquisition, analysis, or interpretation of data for the work; drafting the work or revising it critically for important intellectual content; final approval of the version to be published; agreement to be accountable for all aspects of the work in ensuring that questions related to the accuracy or integrity of any part of the work are appropriately investigated and resolved.

Key words: Coronavirus; ICU: protection.

Received for publication: 24 March 2020.

Accepted for publication: 25 March 2020.

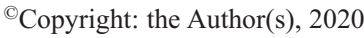

Licensee PAGEPress, Italy

Monaldi Archives for Chest Disease 2020; 90:1284

doi: 10.4081/monaldi.2020.1284

This article is distributed under the terms of the Creative Commons Attribution Noncommercial License (by-nc 4.0) which permits any noncommercial use, distribution, and reproduction in any medium, provided the original author(s) and source are credited. patients and their immediate surroundings, including medical equipment like infusion pumps and ventilators, should be avoided. Using patient monitors on central workstations to monitor vitals and other parameters of treatment may also reduce contact.

\section{Aerosol generating procedures - a breath of 'foul' air?}

Extra care should be taken while aerosol generating procedures. Non-invasive ventilation, high flow oxygen therapy, intubation/extubation, nebulization, open suctioning of airway secretions, bronchoscopy, induction of sputum, bag and mask ventilation, cardiopulmonary resuscitation, etc. have the potential to generate aerosols in high quantity. During such procedures, the use of a respirator, like N95 respirator, has been advised in preference to a facemask [1-3]. Further, the use of viral filters and closed suctioning should always be ensured. Engineering measures like air flow changes and negative pressure air ventilation also help in reducing aerosol quantity in the IC unit.

Hand hygiene and personal protective equipment a tale of two hands, and more

Primary recommendations of thorough hand hygiene $(\mathrm{HH})$ and personal protective equipment (PPE) are of utmost importance. Regarding $\mathrm{HH}$, both alcohol-based hand rubs, or soap and water hand wash have been advised [1-3]. But in case hand are visibly soiled, only the latter should be used. HH should be performed while entering/ and leaving the IC unit, before and after touching patient or patient's immediate surroundings (like bed, infusion pumps, feeding tube, ventilator, urinary catheter, etc.) and before and after performing a procedure on a patient [1-3].

Ideally, all HCPs caring for COVID-19 patients should use a fit tested respirator [2], but in case of shortage, the use of facemasks has been advised [3]. It must be remembered that facial hair (beards) interfere with the fit and render the seal around the facemask useless. ${ }^{[4]}$ As such, it is advisable to keep a close-shave.

When putting together and taking apart are not antipodes

The CDC (Centers for Disease Control and Prevention, USA) has recommended sequences for both donning (putting on) and doffing (removing) PPE [5]. 
For donning, the sequence of HH—gown — mask - gogglesgloves should be followed. Meanwhile, during doffing, the order used should be gloves-goggles-gown-mask-HH. While doffing, extra care should be taken to avoid touching the outside of gloves and the front of the mask, since both are the most contaminated parts of PPE. This recommendation includes wearing goggles for protection against ocular transmission. The evidence of ocular transmission is unclear. Animal studies, however, have shown evidence of ocular transmission and infection. Thus, prevention and protection of eyes is also an integral part of PPE and should not be ignored or missed [6].

\section{Discard or disinfect}

Lastly, the issue of handling patient equipment needs to be addressed. All disposables should be discarded, as per biomedical waste management protocol of the hospital, as soon as their function is complete. Re-useable/non-disposables should be thoroughly disinfected using manufacturer recommendations. Surface cleaning and disinfection should be done frequently in IC units. Visibly soiled surfaces/equipment should be dealt with immediately.

\section{Conclusions}

On $30^{\text {th }}$ January 2020, the World Health Organization (WHO) declared a public health emergency and recently as a global pandemic [7]. India already has crossed 100 patients tested positive as on $15^{\text {th }}$ march 2020 . India is in phase 2 and may soon enter phase 3 of this pandemic, unless curtailed [8]. Looking at the current COVID-19 pandemic data from countries like China, South Korea and Italy to name a few, it is easy to understand that health care systems are put under immense pressure for a continued period of time. As such, ensuring the wellbeing of HCPs is crucial to keep health care system up and running.

\section{References}

1. Centers for Disease Control and Prevention. Coronavirus Disease 2019. Interim Infection Prevention and Control Recommendations for Patients with Suspected or Confirmed Coronavirus Disease 2019 (COVID-19) in Healthcare Settings. Accessed on: 21 $1^{\text {st }}$ March 2020. Available from: https://www.cdc.gov/coronavirus/2019-ncov/infectioncontrol/control-recommendations.html?CDC AA refVal= https $\% 3 \mathrm{~A} \% 2 \mathrm{~F} \% 2 \mathrm{Fwww}$.cdc.gov $\% 2 \mathrm{Fcoronavirus} \% 2 \mathrm{~F} 2019$ ncov $\% 2$ Fhcp $\% 2$ Finfection-control.html

2. WHO. Rational use of personal protective equipment for coronavirus disease 2019 (COVID-19). Accessed on: 21st March 2020. Available from: https://apps.who.int/iris/bitstream/handle/10665/331215/WHO-2019-nCov-IPCPPE_use-2020.1eng.pdf

3. Centers for Disease Control and Prevention. Coronavirus Disease 2019. Healthcare personnel with potential exposure to COVID-19. Accessed on: 21st March 2020. Available from: https:/www.cdc.gov/coronavirus/2019-ncov/hcp/guidancerisk-assesment-hcp.html

4. Sandaradura I, Goeman E, Pontivivo G, et al. A close shave? Performance of $\mathrm{P} 2 / \mathrm{N} 95$ respirators in healthcare workers with facial hair: results of the BEARDS (BEnchmarking Adequate Respiratory DefenceS) study. J Hosp Infect 2020. pii: S01956701(20)30008-6. [Epub ahead of print].

5. Centers for Disease Control and Prevention. Sequence for putting on and removing personal protective equipment. Accessed on: 21st March 2020. Available from: https://www.cdc. gov/hai/pdfs/ppe/PPE-Sequence.pdf

6. Seah I, Agrawal R. Can the Coronavirus Disease 2019 (COVID-19) affect the eyes? A review of coronaviruses and ocular implications in humans and animals. Ocul Immunol Inflamm 2020;1-5. [Epub ahead of print]. doi:10.1080/ 09273948.2020 .1738501

7. WHO. Statement on the second meeting of the international health regulations (2005) emergency committee regarding the outbreak of novel coronavirus (2019-nCoV). Available from: https://www.who.int/news-room/detail/30-01-2020-statementon-the-second-meeting-of-the-international-health-regulations-(2005)-emergency-committee-regarding-the-outbreakof-novel-coronavirus-(2019-ncov)

8. Indian Council of Medical Research. Media report on "Briefing on COVID19" Accessed on: 20th March 2020. Available from: https://www.icmr.nic.in/sites/default/files/ MediaReport_COVID19.pdf 